\title{
An integrative framework for transformative social change: a case in global wildlife trade
}

\author{
Rumi Naito ${ }^{1}$. J Jiaying Zhao ${ }^{1,2} \cdot$ Kai M. A. Chan ${ }^{1}$
}

Received: 4 August 2021 / Accepted: 28 November 2021 / Published online: 20 January 2022

(c) The Author(s), under exclusive licence to Springer Japan KK, part of Springer Nature 2021

\begin{abstract}
To achieve a sustainable future, it is imperative to transform human actions collectively and underlying social structures. Decades of research in social sciences have offered complementary insights into how such transformations might occur. However, these insights largely remain disjunct and of limited scope, such that strategies for solving global environmental challenges remain elusive. There is a need to integrate approaches focusing on individuals and social structures to understand how individual actions influence and are in turn influenced by social structures and norms. In this paper, we synthesize a range of insights across different schools of thought and integrate them in a novel framework for transformative social change. Our framework explains the relationships among individual behaviors, collective actions, and social structures and helps change agents guide societal transitions toward environmental sustainability. We apply this framework to the global wildlife trade — which presents several distinct challenges of human actions, especially amidst the Covid-19 pandemic—and identify pathways toward transformative change. One key distinction we make is between different individual actions that comprise the practice itself (e.g., buying wildlife products; private action) and those that push for a broader system change in practice (e.g., signaling (dis)approval for wildlife consumption; social-signaling action, and campaigning for policies that end unsustainable wildlife trade; system-changing action). In general, transformative change will require an integrative approach that includes both structural reforms and all three classes of individual action.
\end{abstract}

Keywords Pro-environmental behavior $\cdot$ Behavior change $\cdot$ Collective action $\cdot$ Transformative change $\cdot$ Social-ecological systems $\cdot$ Social diffusion

\section{Introduction}

Human activities are major contributors to global climate change and ecosystem degradation, causing unprecedented biodiversity loss and threatening the foundation of our economy, food security, and well-being (IPBES 2019; IPCC 2019). To mitigate climate and ecological crises, transformative change that fundamentally shifts current

Handled by Christopher M. Raymond, University of Helsinki, Finland.

Rumi Naito

rumisen@gmail.com

1 University of British Columbia, Institute for Resources, Environment and Sustainability, 2202 Main Mall, Vancouver, BC V6T 1Z4, Canada

2 Department of Psychology, University of British Columbia, 2136 West Mall, Vancouver, BC, Canada behavioral, economic, social, cultural, institutional, and technological trajectories is necessary (IPBES 2019). However, sustainability transitions are not occurring at the rate or scale required for avoiding catastrophic consequences (UN Environment 2019; United Nations 2019). The current paper presents a multi-directional causal framework that helps understand and identify critical intervention points and transformation processes for environmental sustainability.

Transformative change transcends social science disciplines. It involves changes within individuals including behaviors, personal goals, values, motivations, and perceptions underlying their behaviors (Baker et al. 2019; Kollmuss and Agyeman 2002). It also requires macro-level changes in social structural components, including institutions, laws and regulations, social norms, infrastructures, market mechanisms, and technological innovations (Kendal and Raymond 2018; O'Brien 2015; Olsson et al. 2004). Individual choices and actions can influence the way social structures are established, while social structures provide decision-making 
contexts for individuals (Bandura 1999; Raymond et al. 2014; Seto et al. 2016). Therefore, achieving transformative social change requires an integrative approach that deeply engages with both individual- and structural-level factors because transformations can only emerge from the interaction between them (Giddens 1984; O'Brien 2015).

Many scholars in social sciences have called on multidisciplinary collaborations and the need for a unified framework to scale up social transformation processes (Bennett et al. 2017; Chan et al. 2020; O'Brien 2018; Otto et al. 2020; Swim et al. 2011; Vadrot et al. 2016). Indeed, as we elaborate in the next section, there has been considerable progress in integrating diverse approaches into social-ecological frameworks. However, many existing frameworks do not explicitly explain individual and social structural processes as inseparable components of transformative change. Even when they do, these frameworks are largely theoretical and lack pragmatic applications. Moreover, most frameworks do not distinguish between different types of individual actions that can lead to change in practice itself or create broader societal effects through changing associated social meanings and institutional arrangements.

This paper is an attempt to close the current gap and unify multidisciplinary bodies of theory and evidence into a practical framework. It is organized in four parts. First, we synthesize complementary insights on human action and social change postulated in psychological and sociological literatures and discuss their importance and limitations as a framework for transformative change. Second, we present our integrative framework, unpacking key analytical elements, intervention strategies, and transformation processes for environmental sustainability. Third, we apply the framework to discuss global wildlife trade issues and suggest potential intervention points and high-level solutions. Finally, we reflect on the theoretical implications of the framework for future social-ecological research and practice, its limitations, and potential applications for a wide range of contexts.

\section{Overview of insights on human action and social change}

Current research on human behavior and social change draw upon insights from many disciplines in social sciences. Different approaches can be represented on a continuum between two idealized methodological paradigms in research-referred to as 'reductionism vs. holism', 'agency vs. structure', or 'individualism vs. collectivism' (Archer 1996; Diani and McAdam 2003; Sawyer 2005). Table 1 presents a comparison between these two paradigms, which we see as being both important and necessary for transformative change.

Reductionism is a methodological approach adopted by disciplines, notably psychology, that aim to understand a social phenomenon by reducing it to its elementary components (Sawyer 2005). In this approach, individuals or groups of individuals are the main unit of analysis. Human behavior is reduced to a variety of personal and contextual factors, such as knowledge, values, attitudes, beliefs, norms, laws, infrastructures, and incentives, which together operate as drivers of a behavior (Gifford 2014; Kendal and Raymond 2018; Miller and Prentice 2016). This approach claims that behavior change occurs when one or more of these factors change (Asensio and Delmas 2015; Byerly et al. 2018; Callahan et al. 2019; Fishbein and Ajzen 2010; Thaler and Sunstein 2008). Moreover, behavior change initiated by a large number of individuals can trigger a behavioral cascade and a shift in social norms and practices, potentially leading to a social change (Centola et al. 2018).

On the other hand, holism shifts attention away from individuals and instead focuses on the macro-level context as the main unit of analysis (Sawyer 2005). Holistic approaches study legal, political, economic, and social arrangements and their roles and interactions in shaping a larger system as a whole—not merely as contextual factors

Table 1 Comparison between reductionist and holistic approaches

Reductionist/individual-oriented approaches

Human action is individually driven by internal and external factors (e.g., values, habits, norms)

Unit of analysis

Individuals or groups of individuals

Primary focus

Identifying causal drivers of individual behaviors (microlevel analysis)

Methodology

Social change occurs as the

result of.
Holistic/social structural approaches

Human action is collectively facilitated or constrained by elements of social structures (e.g., laws, infrastructures, technologies)

Social structures and practices

Identifying enablers for social practices and specifying the missing link among the enablers (macro-level analysis)

Descriptive, observational, theoretical

Structural transformation through the modification or creation of key elements of practice 
to explain individual behaviors. This methodological approach treats a social phenomenon as being more than the constellation of individual behaviors and so not reducible to micro-level components (Blake 1999; Hargreaves 2011; Reckwitz 2002). Therefore, the emphasis here is on understanding and designing a whole suite of enablers conducive to sustainable practices, rather than targeting individuals (Baynes et al. 2015; Gruber 2010; Meadows 1999; Ostrom 1990; Sayer et al. 2013).

While each school of thought provides important insights for understanding human behavior and social change, it also comes with limitations. Reductionist or individual-oriented approaches often fail to explain the heterogeneity in the effects of behavioral interventions across different systems (Henrich et al. 2010; Soman and Hossain 2020) and fail to generalize human behavior change from one context to another, contributing to the current replication crises in social sciences (Christensen and Miguel 2018; Maxwell et al. 2015). While reductionist approaches can identify specific factors driving human behavior in a highly controlled environment, it rarely captures the interactions of these factors in real-world contexts, resulting in failed interventions (Hummel and Maedche 2019; Kristal and Whillans 2020; Soman and Hossain 2020; Sunstein 2017). These limitations prevent individually targeted interventions from yielding large-scale social changes (Dubois et al. 2021; Mols et al. 2015). In social-ecological contexts, behavioral interventions are "like an effort to capture a lion with a mousetrap" (Thaler and Sunstein 2008, p.184) and are hardly the right scale to address systemic problems by themselves.

On the other hand, holistic or social structural approaches focus on the big picture and tend to overlook individual differences among people who are an essential part of social structures. It assumes that changes in social structures (e.g., regulations and technologies) would inevitably shift individual behaviors (Shove 2010; Shove et al. 2012), which is often not the case. Such an assumption strips away individual agency and treats people as mere "carriers of practice" (ibid). Another key limitation comes from the lack of causal evidence between social structural enablers and environmental outcomes. Few studies in this realm isolate and objectively evaluate the effects of key attributes-a method commonly adopted in reductionism-because it is impracticable and costly to conduct large-scale experiments in a top-down change model (Agrawal 2014). Rather, they rely on historic accounts of case studies and qualitative methods to evaluate long-term changes in social phenomena (Agrawal 2001; Ostrom 1990). As a result, holistic approaches generally yield more nuanced descriptions of enabling factors, rather than offering clear explanations and causal evidence on how social change occurs.

In the context of envisioning paths toward a broad societal change that involves transformation of all relevant elements, neither reductionist nor holistic approaches alone are sufficient. Given their different implications and methodological strengths and limitations, it is crucial that these two approaches are deeply integrated in social-ecological research and practice. Indeed, since Anthony Giddens' and Albert Bandura's influential frameworks that explained interdependent relationships between personal and environmental factors (Bandura 1986; Giddens 1984), the separation of agency and structure has become less salient. Many social-ecological frameworks have adopted multidisciplinary approaches and become robust in their ability to explain complex systems and relationships among individual, collective, and structural elements. Notably, research on social diffusion and tipping points-an increasingly popular concept in the social-ecological literature-contributes to overcoming the agency-structure dichotomy by emphasizing both individual change and its exponential effects across populations (Milkoreit et al. 2018). Research by Abernethy et al. (2014), for instance, studied the adoption of marine resource management at the community level, providing important insights into both individual community characteristics and institutional arrangements. Table 2 presents examples of such frameworks, selected based on their relevance and influence within the social-ecological literature.

Despite these efforts, however, many existing frameworks are still limited in terms of their scope, practical application, and methodological integration. Our framework adds value to previous contributions in social sciences by bridging these gaps and elucidating multi-level perspectives to address current social-ecological problems.

\section{The integrative framework for transformative social change}

\section{An overview}

In this section, we propose that the process of deliberate transformative change be guided in a multi-directional causal framework in which human behaviors and social structures interact and influence one another. A social structure is a system of coordination for the maintenance and appropriation of resources through formal or informal institutions, socioeconomic and political systems, cultural values, social norms, infrastructures, and technologies (Lin 2001). More generally, a social structure is a decision-making context, enabling or constraining individual and collective actions, which can in turn influence the social structure (Bandura 2001). Materials (e.g., objects, infrastructures, tools, and technologies), competences (e.g., knowledge, skills, and capacity), and meanings (e.g., social norms, values, cultures, and motivations) are key elements of a social structure (Shove et al. 2012). Through complex interactions among 


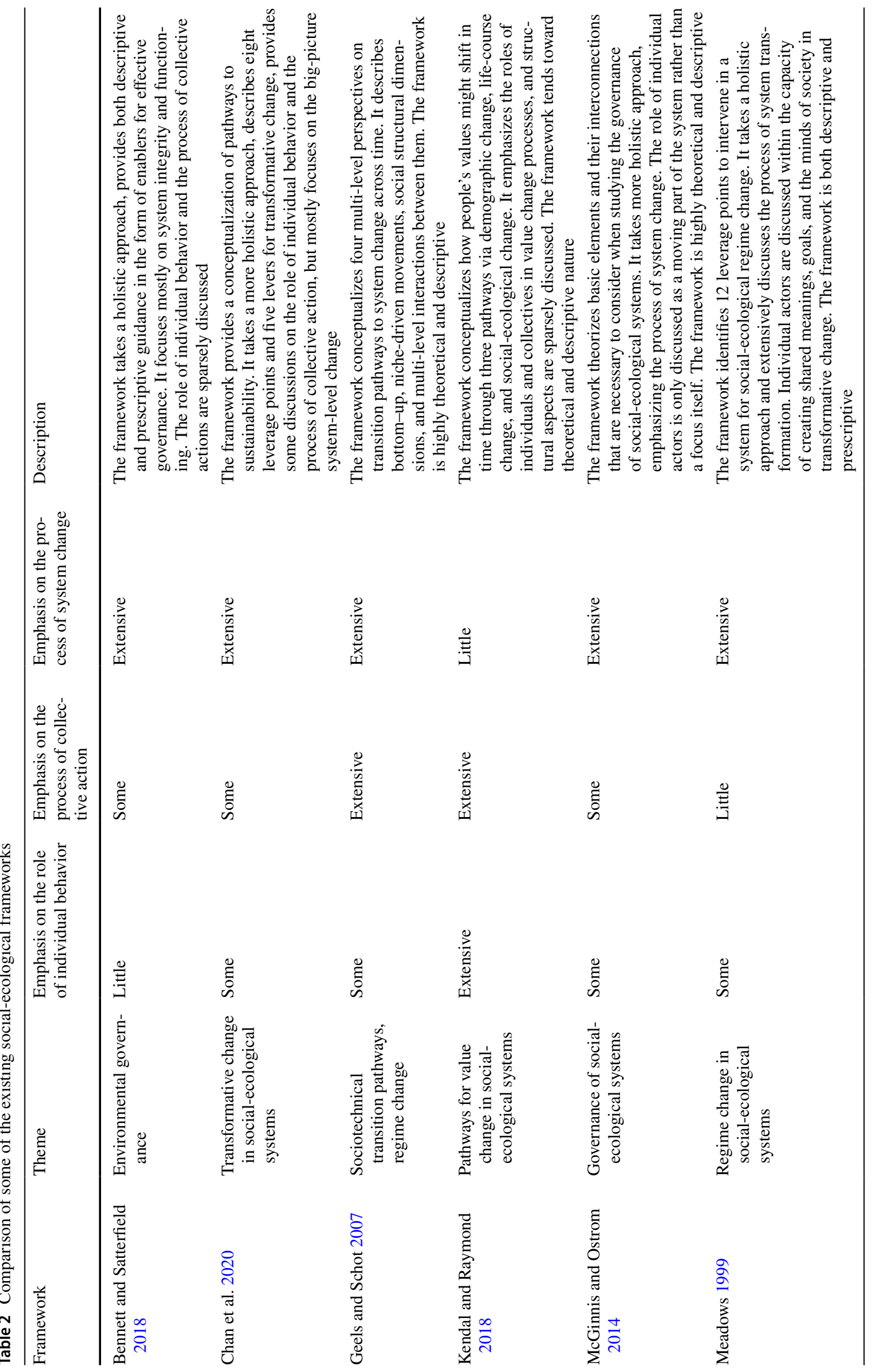




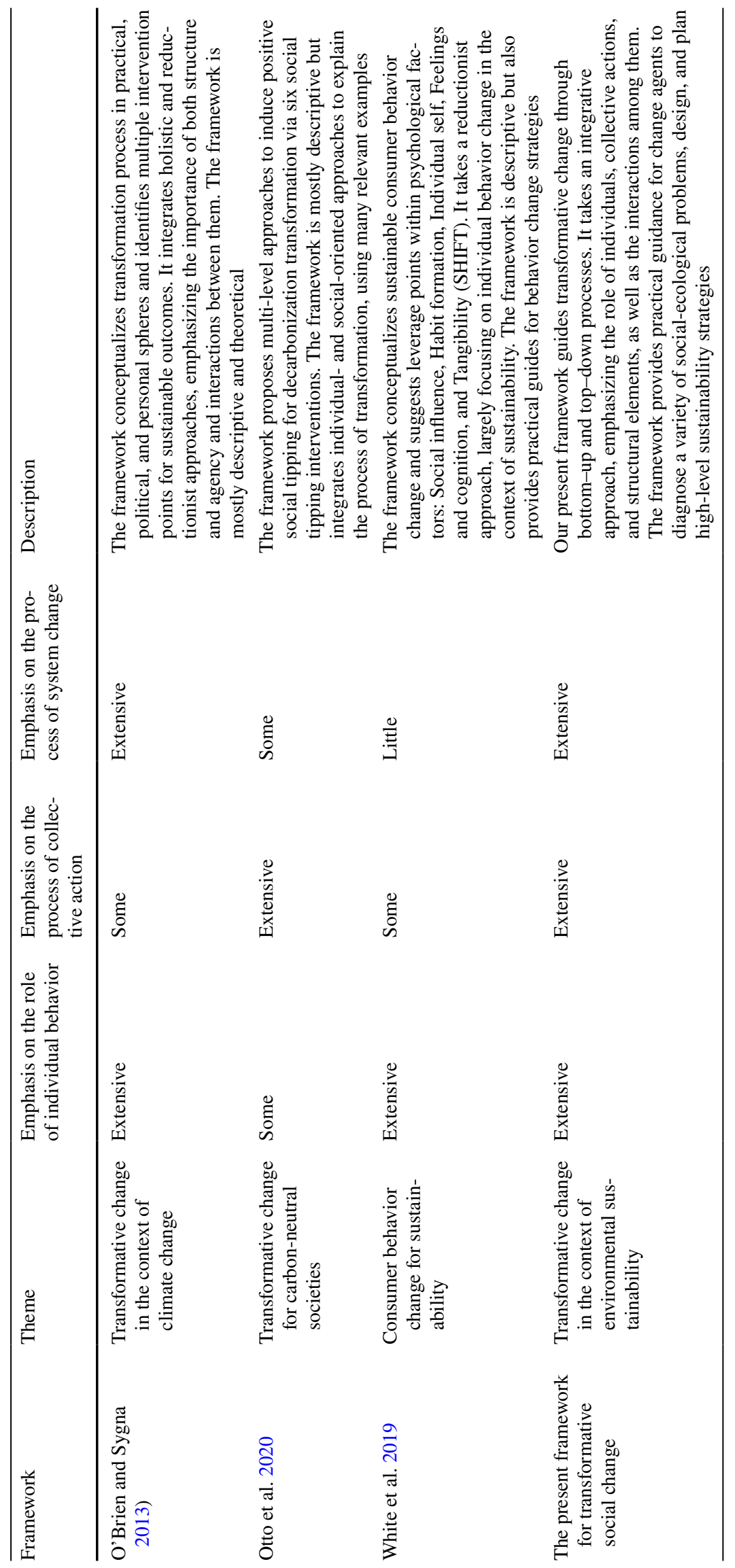


these elements, different practices emerge, evolve, or disappear (Shove et al. 2012).

Figure 1 illustrates the integration of reductionist (individual-oriented) and holistic (social structural) approaches and the interdependent relationships between the structural elements and individual and collective actions. It points out various directions of influence that can instigate deliberate transformative social change. This is the conceptual basis for our social change framework.

The outer gray circles represent the holistic, social structural approaches, whereas the center pink circles symbolize reductionist approaches, highlighting different classes of actions (described below). For example, technological advancements in electric vehicles (change in materials) enhance the capacity to cut down greenhouse emissions in the transportation sector (change in competences). Shifts in material availability and competences make low-carbon transport options more accessible for the public, which can change social meanings about mobility and sustainable lifestyles (change in meanings). Changes in these three elements can motivate people to take a variety of actions, from buying an electric vehicle (private action) to sharing information about the benefits of electric vehicles (social-signaling action) and demanding city-wide transportation electrification through petitions and voting (system-changing action).

There is also a bidirectional relationship between individual and collective actions. Individual actions may lead to the onset of collective actions when enough people act

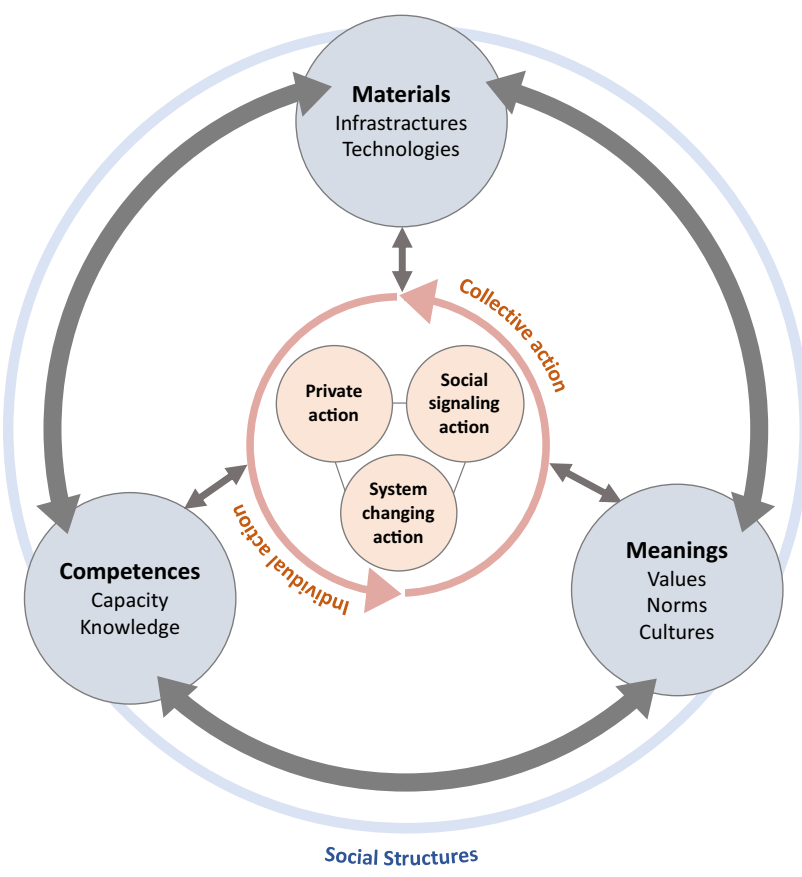

Fig. 1 The interdependent and mutually shaping elements of practice, highlighting three classes of actions for change. Arrows represent directions of influence upon shared objectives. In turn, collective actions, typically organized in social movements and conventions, can motivate individual actions that are aligned with group interests and values. Moreover, individual and collective actions can push for structural change by creating new demand and norms, although the feasibility of these actions often depends on contextual factors such as access to technologies, infrastructures, capital, political power, and economic opportunities. As all these elements are tightly linked, it is impossible to isolate any component from the analysis of transformative social change.

\section{Three classes of individual actions for transformative change}

There are many types of actions that people can take to promote environmental sustainability. Some actions complement individual sustainability goals, while others lead to broader collective pursuits. While these actions tend to be lumped together as pro-environmental actions, they have overlapping but different mechanisms of spurring change. Building on Stern's theory of environmentally significant behavior (2000) and more recent work by Larson et al. (2015), we classify a range of individual actions relevant to transformative change into three distinctive categories: private, social-signaling, and system-changing actions. This classification emphasizes different kinds of contributions people can make as an individual or a group, not only through changing individual choices and behaviors but also through engaging in broader actions for societal effects. Achieving transformative change requires addressing each class simultaneously.

Private actions are behaviors that people privately conduct to reduce their own environmental impacts (e.g., recycling, water and energy saving, and environmentally conscious purchasing). These actions can incidentally contribute to a shift in demand patterns, but they do not necessarily create intentional ripples that spread outwards through social networks. Hence, many private actions are limited to individual-level choices and do not address structural problems.

Social-signaling actions are behaviors that people conduct to publicly share and signal their pro-environmental values, attitudes, identities, and opinions (e.g., 'liking' and sharing on social-media, participating in general events such as Earth Day, and wearing stickers, badges, and T-shirts with environmental messages). These actions can contribute to spreading social norms and meanings of practice aligned with a sense of responsibility and proenvironmental values (Klain et al. 2017). Social-signaling actions have the potential for norm change that inspires other actions. 
System-changing actions are behaviors that people collectively engage in with the intent of changing laws, policies, corporate actions, institutions, and infrastructure (e.g., petition signing, voting for progressive parties, civil disobedience and other direct environmental activism, and donation to system-changing environmental organizations). These actions can inspire broader system change and indirectly influence behaviors of many populations through policies, institutions, and physical infrastructures.

\section{The framework}

Our framework offers integrative, descriptive, and practical guidance for change agents (e.g., policymakers, practitioners, individual activists, and researchers) to understand and engage in dynamic processes of social change for environmental sustainability (Fig. 2). The orientation of the framework depends on where the work of change agents is situated, and hence, the framework does not represent interests of particular groups.

The framework draws upon a vast body of theories of human action and evidence, emphasizing individual agents' roles in affecting social-ecological systems and structural arrangements in enabling or constraining actions. Although the framework offers limited advances in theory, it provides three key points of novelty. First, it distinguishes between three classes of individual actions in broader pro-environmental transformation processes and explains how each type of action contributes to greater societal effects. Second, in contrast to the largely descriptive frameworks reviewed above, our framework guides change agents to locate their initiatives in the context of system feedbacks and to identify key intervention points and high-level strategies at both individual and structural levels. However, designing specific interventions will require empirical assessments of each case, which is beyond the scope of this framework.

The third point of novelty is our framework's representation of social norm formation, which involves dynamic processes of meaning and value change at multiple levels. Behavioral and structural change can foster relational values held by many people - notions of appropriate or desired relationships with nature (Chan et al. 2020). Unleashing social norms and relational value can, therefore, be a powerful step toward widespread change because these latent values can influence group behaviors over a long term (Chan et al. 2020; Kinzig et al. 2013; Legros and Cislaghi 2020; Nyborg et al. 2016; Young 2015). While this representation builds upon previous frameworks of social change, our framework explicitly treats both individual and social structural processes as crucial elements for system feedbacks.

\section{Behavioral intervention processes}

Change agents must first understand why people behave the way they do and identify psychological barriers and enablers for behavior change before designing interventions (Datta and Mullainathan 2014; White et al. 2019). Past research show that human decisions are subject to cognitive biases and heuristics. For example, people tend to pay more attention to information that confirms their prior beliefs, ignore information that contradicts their existing views and behaviors, conform to the opinions of their peers, and use intuition when judging what is right or wrong (Festinger 1957; Haidt 2001; Kunda 1990; Lord et al. 1979; Turner et al. 1987; Tversky and Kahneman 1974). Such cognitive biases and heuristics allow people to navigate through massive information complexity and efficiently make decisions without solely relying on rational reasoning (Levine et al. 2015).

Interventions that harness cognitive biases and heuristics can produce behavior change. For example, messaging that uses iconic photos and narratives can trigger emotional reactions and draw attention more effectively than those that only provide facts and statistics (Slovic et al. 2017). Reminders and change in default settings can reduce mental efforts in decision-making and nudge people to take desired actions (Shah and Oppenheimer 2008). Particularly, structural interventions that alter default settings or infrastructures are effective at reducing the attitude-intention-behavior gap-inconsistencies where people's values, attitudes, and intentions do not translate into actual behaviors-and eliciting actions (Blake 1999; Kollmuss and Agyeman 2002; Vigors 2018). Similarly, interventions that leverage social norms and group identity are found effective at guiding public behaviors (Shakya et al. 2017; Young 2015). Injunctive social norms operate as a signal of what is right or acceptable to do (Cialdini and Goldstein 2004). If a sustainable practice is perceived as an incentive (e.g., social recognition as a responsible citizen) rather than a tax (e.g., burden), the practice can be readily accepted and spread across societies, potentially triggering a norm cascade (Sunstein 2020).

While behavioral interventions do not directly influence structural interventions, they can indirectly inspire structural change by mobilizing a large number of people to take proenvironmental actions and by shifting social norms. Individual behavior change can, therefore, operate as structural interventions through diffusion processes, which can lead to a norm cascade and create public demand for structural change.

\section{Structural intervention processes}

Social structures can lock in most forms of social interactions and practices for a long period of time, providing contexts to social norms, meanings, and cultural values that all 


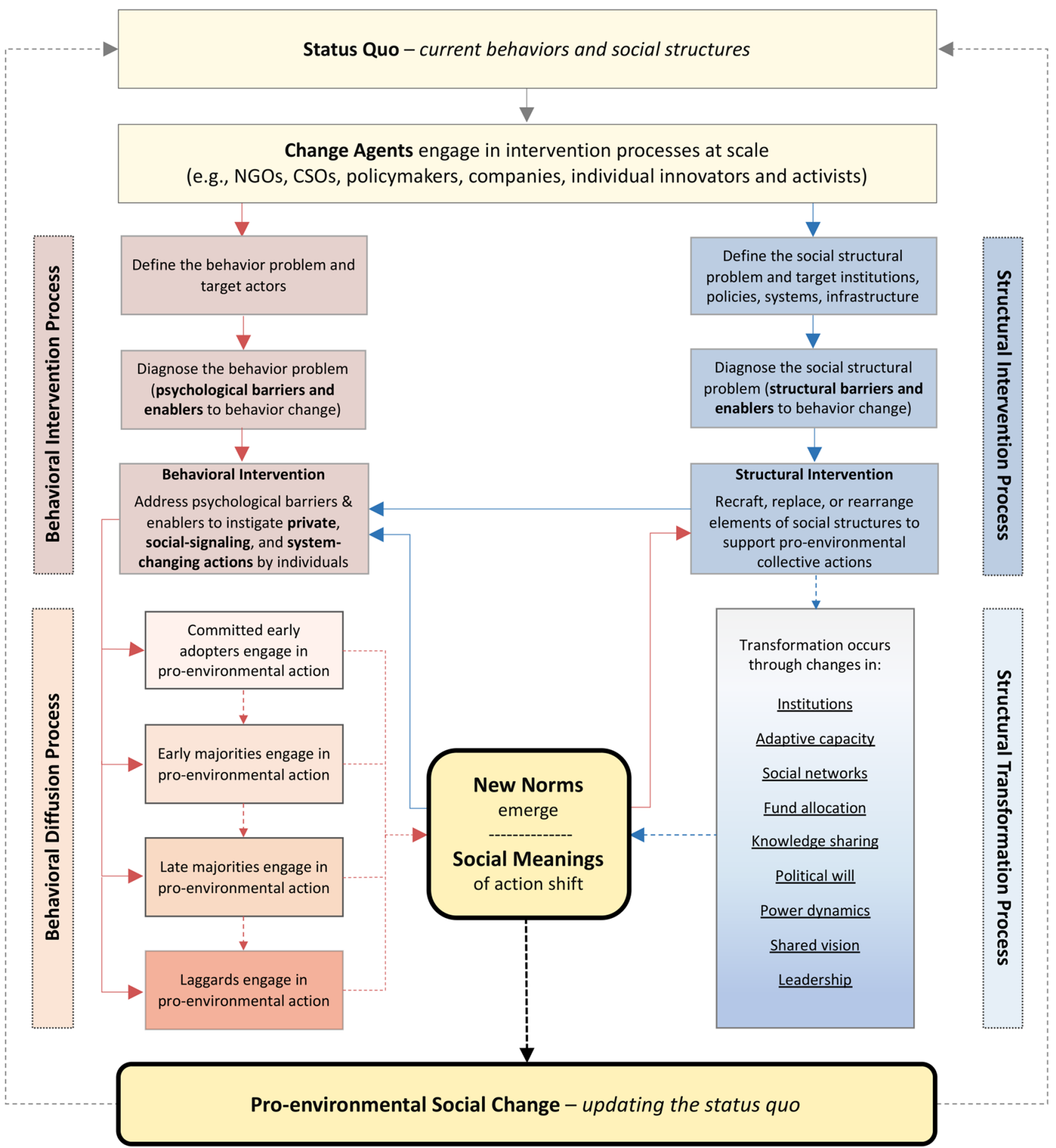

Fig. 2 Integrative framework for pro-environmental social change. Solid line arrows represent directions of influence, and dotted line arrows represent potential (desired) outcomes. Red arrows indicate

function as standards of behavior within societies (O'Brien 2018). Interests of powerful actors are frequently favored by institutional rules and norms, through which their socioeconomic and political dominance is reinforced and stabilized (Pierson 2000; Seto et al. 2016). Therefore, in the structural individual behavioral change and behavioral diffusion processes and influences, whereas blue arrows represent structural processes and influences

intervention processes, change agents must understand how institutions, socioeconomic systems, power dynamics, infrastructures and technologies are arranged and how they facilitate conditions in which social-ecological problems occur (Seto et al. 2016). 
Once structural barriers and enablers for behavior change are identified, it is possible to target intervention points within social structures. Here, it is important to intervene in social structures at different administrative and geographical scales, ranging from local to global, so that pro-environmental initiatives are well coordinated and supported across various jurisdictional and institutional boundaries (Bodin 2017). Without collaborative structures and a good alignment of cross-scale systems, structural interventions can be fragmented and fail to achieve desired transformations (ibid).

Structural interventions involve modifying relevant or competing elements of practice and their interlocking arrangements within a social structure (Hargreaves 2011). In the low-carbon development sector, for example, high costs, market risks, incomplete information, infrastructural limitations, and unfavorable fiscal and regulatory policies deter the deployment of green technologies, allowing few innovations to survive the transition from invention to largescale application (Brown et al. 2008). These obstacles are often manifested in entrenched patterns of social structural arrangements that disrupt innovation and competitiveness of low-carbon alternatives (Seto et al. 2016). Removing such barriers is crucial for enabling the rapid and large-scale adoption of pro-environmental practices.

Moreover, structural interventions can directly engage with individual behavior change by disrupting people's old habits and routines and creating alternative decision-making settings (Lockton et al. 2010; Thaler and Sunstein 2008).
For example, a well-maintained, affordable, and convenient transit infrastructure (e.g., bicycle lanes, bus networks) can motivate people to switch from driving cars to a low-carbon transportation alternative (Sunstein and Reisch 2014). Similarly, higher taxes on gasoline can make driving a less attractive option than taking public transportation. In this sense, structural interventions can directly operate as behavioral interventions, potentially supporting large-scale behavior change.

\section{Behavioral diffusion processes}

Behavioral diffusion processes require specific strategies for different segments of a population and phases (Abernethy et al. 2014; Zhao et al. 2021). Successful behavioral diffusion tends to move through five stages (Fig. 3): the initiation of a new behavior by innovators or 'change agents', the adoption of the behavior by early adopters, by the early majorities, by the late majorities, and then by laggards (Rogers 1958; Ryan and Gross 1943). In social-ecological contexts, early adopters of sustainable practices tend to be committed individuals who hold strong environmental values and a sense of responsibility for environmental stewardship and care for wildlife, land, and water (Chapman et al. 2019). The early majorities are individuals who are socially connected with early adopters or organizations that advocate for environmental stewardship (Abernethy et al. 2014). The late majorities are people who follow the actions of others, and

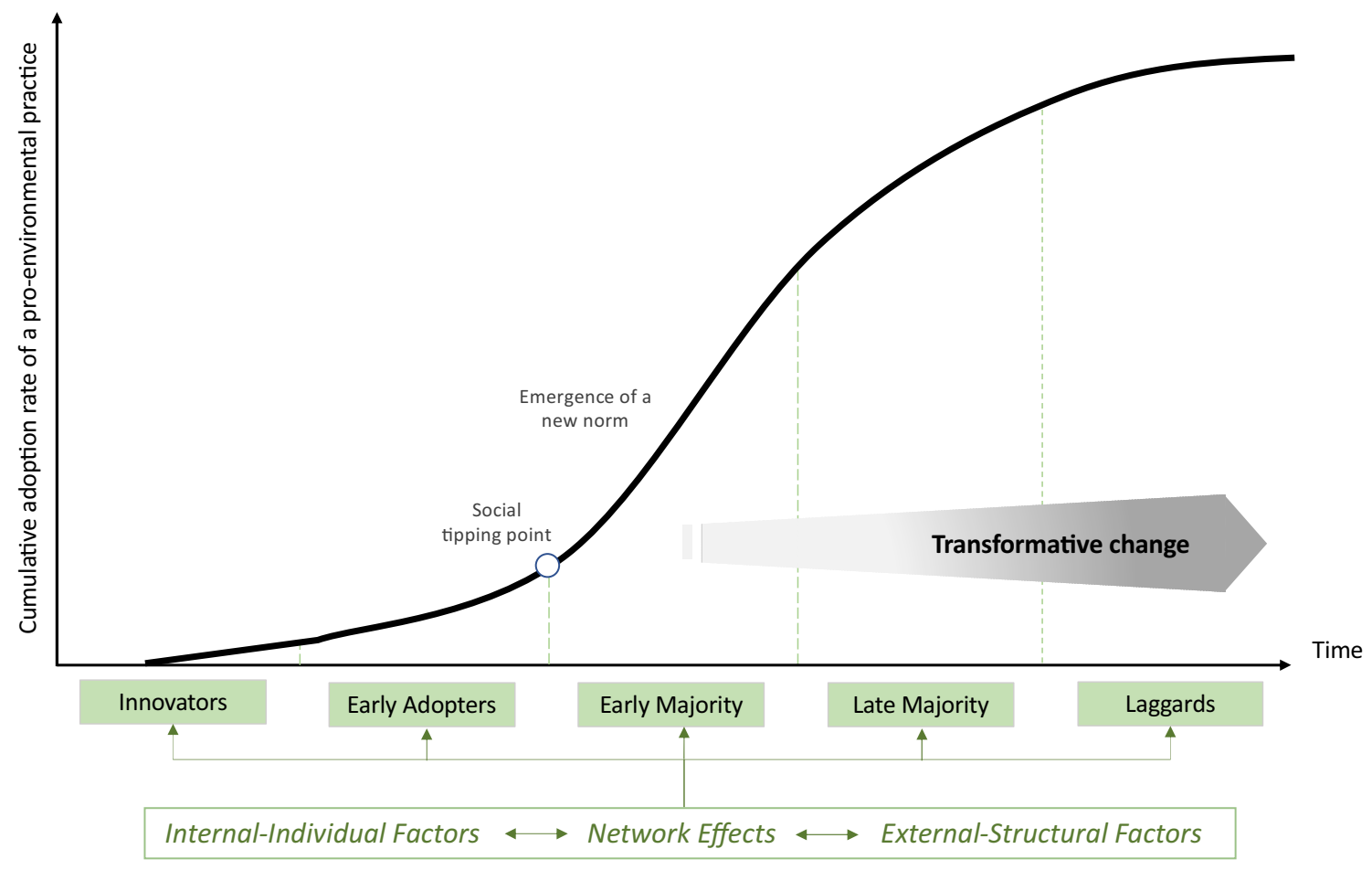

Fig. 3 The diffusion of pro-environmental practice, adapted from Rogers (2003) 
laggards are those who only adopt sustainable practices if there is coercion (e.g., laws and regulations) or a significant social pressure to do so (Rogers 2003). However, what is presented as adopter characteristics here depends on contexts, which may include substantial social, economic, and political constraints. For example, regardless of their proenvironmental values and social networks, many rural and impoverished communities lack the ability to adopt sustainable practices due to significant economic hardships (Waylen et al. 2013).

Psychometric segmentation, a common marketing technique that involves clustering a population based on preferences, attitudes, motivations and behaviors, can help change agents understand similarities and differences among actors and design more targeted communications (Baker et al. 2019; Kidd et al. 2019). For instance, messages framed to activate a sense of environmental values and identities can be particularly effective at engaging with people who are early adopters or the early majorities (Chapman et al. 2019; Teel and Manfredo 2010). However, such message frames are unlikely to have the same effect on the late majorities or laggards (Kidd et al. 2019). Strategies such as incentives, social pressure, and the knowledge of law and peer consensus are more effective at influencing judgements and promoting sustainable behaviors among these segments of the population (Berkowitz and Walker 1967; Cialdini and Goldstein 2004; Davis et al. 2018; Jayachandran et al. 2017; White et al. 2019). Here, it is important to note that shifts in value orientations, attitudes, and motivations can occur as a result of behavior change (Kendal and Raymond 2018; Sussman and Gifford 2019). As people adopt sustainable practices, their perspectives and attitudes toward environmental issues can change, updating their prior attitudes and beliefs.

Moreover, behavioral diffusion processes are likely to be more effective if interventions are applied to individuals or organizations via existing social networks (Kim et al. 2015; Ryan and Gross 1943). A social network is a "pattern of friendship, advice, communication or support which exists among the members of a social system" (Valente 1996). Interventions which engage with social leaders in the early stage are found to be more successful at gaining community support and achieving group behavior change than those that do not (Abernethy et al. 2014; Paluck et al. 2016). This suggests that social-ecological interventions can also benefit from engaging in behavioral diffusion processes through social networks (Mascia and Mills 2018).

Social change can occur as a result of a single event or an act of a committed person or group that triggers a cascade of collective actions through social networks (Diani and McAdam 2003; Granovetter 1978). Once a sufficient number of people accept a new practice, a new norm can emerge and spread exponentially throughout the population, exceeding a social tipping point (Centola et al. 2018;
Sunstein 2020; Xie et al. 2011). This can further instigate public actions by which people demand more sustainable alternatives, a new set of rules and industry standards, and ultimately system-wide changes (Heidbreder et al. 2019). In other words, the successful initiation of collective action and the diffusion of new norms and sustainable practices can start from the bottom up, creating institutional and industrial reforms which can further reinforce sustainable practices (Davis et al. 2018).

Some of the most successful environmental movements in modern history have followed similar patterns. For example, a wave of public outcry for controlling ozone-depleting chemical substances pushed the governments around the world to collectively ban the industries against the use under the Montreal Protocol of 1987 (Buranyi 2018). Pro-environmental social change can happen if behavioral interventions successfully mobilize a large group of people to engage in collective actions and if social structures effectively respond to the demands of majorities (Chenoweth and Stephan 2011; Diani and McAdam 2003).

\section{Structural transformation processes}

Although structural transformation can be a long and slow process, its impact on social-ecological systems can be substantial and can lock in sustainable practices for a long period of time. The mechanisms underlying structural transformation within social-ecological systems include governance changes through the co-management of natural resources (Olsson et al. 2004). Key elements of effective governance include institutional capacity for monitoring and responding to environmental change, knowledge sharing, political will, mobilization of adequate funds and technologies to support change, and stable social networks with shared visions and strong leaderships (Abson et al. 2017; Bennett and Satterfield 2018; Díaz et al. 2019; Olsson et al. 2004). Changes in these elements will lead to the emergence of new rules and structural functions, reinforcing the norms and meanings that support pro-environmental practices (Young 2015). As new social norms emerge and dissipate, pro-environmental practices can be institutionalized and achieve long-term stability. This creates positive feedbacks, whereby institutions enable more sustainable practices to spread and persist, further cementing sustainable pathways (Young 2015). However, there are many cases of path dependence in social processes by which prevailing institutional, infrastructural, technological, and behavioral arrangements obstruct change and make the cost of reversal very high (Pierson 2000; Seto et al. 2016). Reversing the current system requires significant efforts and investments, including eliminating subsidies and policies that favor the status quo, divesting from environmentally destructive assets, building sustainable cities 
and infrastructures, and modifying entrenched social norms (Otto et al. 2020; Seto et al. 2016).

\section{Toward pro-environmental social change}

To achieve transformative change for sustainability, it is critical to treat both structural and behavioral interventions as interactive long-term processes rather than a quick fix. Meadows (1999) argues that the goals of the system and the mindset of people from which system arises are potentially the most powerful places to intervene in shifting paradigms. This point brings our attention to the interaction between structural interventions and individual behavior change. Transformative change requires the diffusion of sustainable behaviors or actions from niche to mainstream populations. It also requires structural transformations that support a range of sustainable practices at the societal level. When widespread individual actions and structural changes occur simultaneously, meanings of action and norms can shift. Such a shift can lock in alternative development trajectories towards a sustainable future, updating existing behaviors and social structures and reinforcing pro-environmental values and practices across societies.

Our framework suggests that transformative change may be initiated from any point along the structural or behavioral intervention processes but will eventually require changes in all components that leads to the formation of new proenvironmental norms. However, effecting change in these processes is likely to take some time and effort. Some of these elements such as laws and policies cannot be changed without having a broad base of popular support from the civil society because most governments have limited capacity to change social structures, norms, and meanings unilaterally. Therefore, transformative change is likely to involve many disputes and negotiations between different groups of people who hold opposing environmental views and vested interests in the status quo (IPBES 2019). When faced with strong oppositions, the processes of change may not easily move beyond the behavioral and structural intervention stages.

\section{The application of the framework to the global wildlife trade}

In this section, we apply our integrative social change framework to analyze problems regarding the illegal or unsustainable global wildlife trade and discuss potential intervention points for transformative change. Here, we do not intend to explore a full scope of issues or highlight successful cases that have achieved transformative change in practice because of limited evidence for such successes. Instead, we suggest hypothetical high-level solutions to illustrate the framework's potential application.

\section{The context}

The global wildlife trade is a multibillion-dollar business of the sale or exchange of wild fauna and flora (CITES 2019), driving ecosystem degradation, pushing species toward extinctions, spreading zoonotic diseases such as the novel coronavirus SARS-CoV-2 (i.e., the etiologic agent of Covid19), and causing severe welfare issues and deaths in wild animals (Baker et al. 2013; Dobson et al. 2020; van Uhm 2016). In particular, the global wildlife trade is currently under unprecedented scrutiny because of the potential role it plays in the ongoing Covid-19 pandemic (IPBES 2020; Nuwer 2020). In response to increasing international pressures to tackle the illegal or unsustainable trade, substantial measures have been taken at both local and global levels. These measures include antipoaching initiatives, incentive or alternative livelihood programs, law enforcement, demand reduction campaigns, and trade restrictions through national legislations, and voluntary framework under the United Nations Convention on International Trade in Endangered Species of Wild Fauna and Flora (CITES) (Challender and MacMillan 2014). Despite these efforts, millions of wildlife species continue to be traded illegally or unsustainably to satisfy consumer demand (Kitade and Naruse 2020; Krishnasamy and Zavagli 2020). Trade restrictions and law enforcement are failing in many instances due to weak judicial systems, corruption, and high profit margins, indicating that top-down measures are inadequate as the sole solution (Challender and MacMillan 2014; Hübschle 2017). Similarly, bottom-up measures to reduce demand and supply for wildlife products are also insufficient, merely resulting in negligible changes in consumer behaviors (Greenfield and Veríssimo 2019; Veríssimo and Wan 2019; Veríssimo et al. 2020). Most interventions to date have focused on either top-down or bottom-up strategies without integrating them as an interdependent process to achieve transformative change (Challender and MacMillan 2014; Roe and Booker 2019). Efforts to mitigate threats to wildlife and biodiversity require a systems approach that simultaneously targets complex elements of the global wildlife trade along the supply chain (McNamara et al. 2016; Sas-Rolfes et al. 2019), while also attending to the roles that individuals play through their choices, motivations, and environmental values.

\section{Problem diagnosis}

\section{Social structural dimensions}

One issue pertaining to the illegal or unsustainable global wildlife trade is the lack of effective governance and law 
enforcement. Actors who belong to transnational networks with links to political and economic elites frequently exploit regulatory loopholes, using formal channels to trade wildlife products illegally (Hübschle 2017; Tittensor et al. 2020). Weak and ineffective law enforcement with few repercussions from authorities also exacerbate the occurrence of poaching and illicit sales and possessions in protected wildlife species (Freund et al. 2017). Moreover, trade restrictions can create informal economies that drive transactions underground, making it more difficult to monitor and regulate illegal activities (Roe et al. 2020).

For example, more than 100 orangutans (Pongo abelii, $P$. pygmaeus, and P. tapanuliensis) are estimated to be trafficked and held captive for the pet trade per year, although the trade in orangutans is prohibited by signatory nations to CITES (Freund et al. 2017). The large number of orangutans confiscated by authorities implies that measures to address wildlife crimes and unsustainable practices have been broadly ineffective. This is partly because orangutan traders and owners are rarely caught and prosecuted (Nijman 2017). Even when they are prosecuted, sentences are usually too light compared to the value of the wildlife, failing to function as a deterrent for future crimes (Nijman 2017). Significant disparities between costs and benefits, inconsistent enforcement, inadequate financial resources to perform duties, and structural continuity that ensures profitability of the trade and power accumulation of particular groups impede necessary changes to current practices (Freund et al. 2017).

Although top-down measures are important, they are often disconnected from cultural traditions and norms, lacking social legitimacy among key stakeholders (Hübschle 2017). These measures tend to disproportionately penalize the vulnerable populations who rely on wildlife trade for their livelihoods, while shifting the attention away from wildlife habitat loss as the primary driver of biodiversity loss (Chomel et al. 2007; Koh et al. 2021; Roe et al. 2020). Socially and economically marginalized communities face more serious consequences of law enforcement and trade restrictions because their access to natural resources and food security are threatened and their livelihoods become criminalized (Witter and Satterfield 2018). Therefore, a blanket ban on wildlife trade is unlikely to be an effective solution to addressing social-ecological problems involved in the practice (Eskew and Carlson 2020).

\section{Behavioral dimensions}

Another dimension of the global wildlife trade relates to the decisions and actions of people along the trade chain, including suppliers (e.g., harvesters), intermediaries (e.g., traders, transporters, wholesalers, and retailers), and consumers (McNamara et al. 2016; Sas-Rolfes et al. 2019). Each actor has distinct motivations underlying their involvement in wildlife trade, and therefore, no single intervention works for everyone (Doughty et al. 2019; Kidd et al. 2019; ThomasWalters et al. 2020; Veríssimo et al. 2020). Moreover, behavior change strategies that broadly treat people as consumers of wildlife products are limited, because the majority of the general public are neither direct consumers nor do they even realize when they are (GlobeScan 2020; Wang et al. 2020). This suggests a need for more targeted approaches to influencing actions of people not only through their consumption choices but also through other means including social-signaling and structural measures.

People face a variety of psychological barriers to all three classes of action, including limited cognition, conflicting values, and perceived social, physical, and financial risks (Gifford 2011). For example, exotic pet owners may be unaware that the purchase and possession of certain species are illegal. Ignorance about the legal status of the exotic pet trade can be a barrier to avoiding the purchase of wild animals (private action) (Moorhouse et al. 2017). Similarly, if people do not believe their actions would have much impact, they may not share information about the social-ecological consequences of the exotic pet trade with others (social-signaling action) or may not campaign for policies that would end the exotic pet trade (system-changing action). Such psychological barriers need to be carefully diagnosed empirically on a case-by-case basis and be addressed through behavioral interventions.

\section{Potential solutions}

\section{Structural interventions}

In structural intervention processes, change agents target socioeconomic and institutional factors including regulatory impediments in the current system governing the global wildlife trade. Trade restrictions and law enforcement efforts become effective if other enabling conditions for sustainable practices are also in place and if the livelihoods of actors along the trade chain are protected; that is, there is sufficient flow of funds to monitor illegal or unsustainable activities, conservation officers have the capacity to manage resources and enforce laws, local communities have access to rights and natural resources, there is horizontal and vertical coordination among institutions and sectors at jurisdictional, national, and international levels, and there is a significant demand reduction in wildlife products (Challender and MacMillan 2014). All these conditions are likely to reinforce the legitimacy of structural approaches to promoting sustainable practices.

Instead of imposing a complete ban on wildlife trade, government institutions might regulate the conditions of live wildlife markets and the sale of certain species that threaten 
public health and biodiversity (Aguirre et al. 2020). This also requires strict law enforcement with greater consequences of the illegal or unsustainable wildlife trade in CITES-listed species such as orangutan (Nijman 2017). Meanwhile, legal trade should be adaptively monitored and evaluated, ensuring sustainability of the harvest through mandatory standards and guidelines. Taxes and government policies might be devised to incentivize sustainable practices, while creating a trade environment in which unsustainable products become more costly. However, such structural interventions must be carefully implemented together with alternative economic plans that safeguard rights and livelihoods of vulnerable communities.

\section{Behavioral interventions}

In this process, it is crucial that change agents target various segments of populations differently, while promoting private, social-signaling, and system-changing actions to elicit change at multiple levels and scales (Zhao et al. 2021).

Messaging and nudging are found to be effective at motivating actions among the majority of populations. For example, messages that highlight zoonotic disease risks and legality concerns can enhance knowledge about the socialecological consequences of the global wildlife trade and reduce the demand for exotic pets by up to $40 \%$ (Moorhouse et al. 2017). Similarly, messages that clearly communicate individuals' ability to make a difference can increase people's motivation and intention to take sustainability actions (Schutte and Bhullar 2017). If inaction is partially caused by choice overload (i.e., there are too many priorities to choose or too many ways to contribute), nudges can help people navigate through complex situations and avoid decision fatigue by simplifying decision-making or changing the presentation of information (van Gestel et al. 2020). Such psychologically informed strategies are increasingly popular in public campaigns by organizations that promote sustainable consumption or reduce demand for wildlife products (Lertzman and Baragona 2016; TRAFFIC and The Behavioural Insights Team 2019).

Although messaging and nudging may influence decisions and actions of many, these strategies are unlikely to have the same effect on people who strongly favor wildlife consumption, including traditional medicine users, exotic pet owners, and wildlife product collectors (Doughty et al. 2021). Engaging with this segment of the population (i.e., laggards) is also necessary as they represent a key stakeholder group in the global wildlife trade. Thus, to influence attitudes and behaviors of wildlife consumers, our framework suggests interventions that focus more on structural measures rather than value-based messages and simple nudges. For example, in addition to enforcing legal deterrents for the trade in illegal or unsustainable wildlife products, change agents might engage with authorities from the traditional medicine community (e.g., doctors) as "messengers" to recommend substitutes for wildlife products that provide equivalent benefits (Burgess et al. 2019; Wang et al. 2020).

Behavioral intervention processes are also relevant when engaging with suppliers of wildlife products (e.g., rural community members, farmers, hunters). Conservation programs often use a combination of socioeconomic incentives, such as Payment for Ecosystem Services (PES), to motivate suppliers to adopt sustainable practices (Grima et al. 2016). Local resource users are found to be more supportive of wildlife conservation when their livelihood needs are met and when they receive substantial benefits from the programs (Handberg and Angelsen 2019; Naidoo et al. 2016; Störmer et al. 2019). Behavioral sciences can help further amplify the effects of such incentive-based approaches (Green et al. 2019). However, provision of incentives and alternative income requires scrutiny because it can backfire or weaken intrinsic motivations of community members for protecting wildlife and their natural habitats without incentives (Agrawal et al. 2015; Ezzine-de-Blas et al. 2019). Such motivational crowding in incentive-based approaches can negatively affect human-nature relationships, if they are not properly designed (Chan et al. 2017; Chervier et al. 2019).

To design behavioral interventions, change agents may first identify target behaviors among suppliers or communities as a group: that is, private actions (e.g., uptake of sustainable livelihood options as alternative income sources), social-signaling actions (e.g., sharing information and voicing the support for wildlife conservation with other community members), and system-changing actions (e.g., electing local representatives who prioritize wildlife conservation). Interventions that target each type of supplier or community actions through a combination of behavioral and structural measures can yield greater impacts on changing individual decisions and practices as well as creating collective norms. For example, change agents might frame messages to reflect local values, identities, and interests, harness local pride to protect wildlife species, choose appropriate messengers, simplify information and choices about sustainable livelihood options, or promote social norms for wildlife conservation by enhancing visible signaling (Rare and The Behavioural Insights Team 2019).

\section{Behavioral diffusion and structural transformation}

Transformative change can occur as a result of combined effects of top-down and bottom-up approaches. Top-down approaches play a substantial role in not only regulating the trade itself but also shaping public attitudes and perceptions toward wildlife consumption (Rizzolo 2021). Trade bans on the consumption of wild animals, as seen in China's 
response to the Covid-19 pandemic, can decrease the social acceptability of the wildlife trade and increase people's willingness to find alternative products (Rizzolo 2021; Wang et al. 2020). In other words, the stigmatization of wildlife consumption can influence choices people make and reduce the demand (Moorhouse et al. 2017; Rizzolo 2021). In turn, bottom-up approaches through individual and collective actions can push for change in government policies, regulations, industry standards, and other social structural elements (Lounsbury et al. 2003). The Covid-19 pandemic has shown how social norms and meanings of daily practices can shift abruptly (Casoria et al. 2021; Sunstein 2020), putting a spotlight on the global wildlife trade and instigating a public outcry for a stricter control over illegal or unsustainable wildlife consumption globally (Nuwer 2020). Social norms and meanings that align closely with sustainability goals enable both institutional and individual behavior change needed to address wildlife trade issues.

Current global wildlife trade practices might change their courses toward more sustainable trajectories if societal shifts occur at both behavioral and structural levels. Such a comprehensive approach is necessary to ensure that participation in illegal or unsustainable wildlife trade is not only difficult but also that it is seen as socially unacceptable. Our integrative framework points out the directions and interactions of change in individual behaviors, collective actions, and social structures that together compose critical pieces of transformation for wildlife management.

\section{Theoretical implications and limitations of the framework}

The present framework guides change agents to design effective intervention strategies in a broad set of social-ecological contexts. It has a potential for much wider application in different contexts as it draws on general principles of social sciences, particularly psychology and sociology. For instance, it can be applied to address issues concerning climate change, land-use management, fisheries, biodiversity conservation, waste management, and pollution. The framework is also scalable to target local to global actors as well as grassroots to multilateral initiatives.

Although the framework suggests robust approaches to transformative social change, it has some limitations. First, this approach requires multidisciplinary collaboration with a wide range of stakeholders. This also means that policymakers, lawmakers, grassroots organizations, and all other supply chain actors must be involved in the change process. The coordination and collaboration among many stakeholders are crucial but also very difficult to achieve in practice. Although there are some examples of organizations that have assembled and become institutionalized to make changes within supply chains, such as the Roundtable on Sustainable Palm Oil (RSPO), most initiatives are neither effective nor grounded in this kind of integrative approach. Such fragmented efforts can pose a variety of practical challenges in implementation.

Another challenge concerns the mismatch between longterm nature of social-ecological programs and short-term funding opportunities that they often depend on (Boedhihartono et al. 2018; Dayer et al. 2018). Transformative change can only occur after significant efforts are made at both structural- and behavioral-level processes. This will inevitably require long-term commitments from local, national and international actors including individuals, policymakers, NGOs, private and public sectors, researchers, and funding agencies. However, the current funding structures generally reward projects that generate impacts rapidly (Craigie et al. 2015). This makes the application of the framework rather difficult, especially when the capacity to change is low and long-term support for building a positive feedback of social change is lacking.

Despite these limitations, however, the present paper explains that transformative social change is attainable so long as there are rigorous efforts to intervene in individual behaviors, collective actions, and social structures simultaneously. Approaches that fail to address all these components as part of the unified process are unlikely to yield transformative change, although small-scale initiatives can produce incremental changes. Moreover, these approaches need to be coupled with concerted efforts among all stakeholder groups because the future of the world's ecosystems depends not only on the practice of one group but also of every individual and organization that has vested interests in sustainable way of life. Our framework helps change agents understand how their work might intersect with other initiatives within transformation processes. It also points to key strategic directions and types of support and collaborations they need to amplify their overall impacts.

\section{Conclusion}

Past studies have made theoretical and empirical contributions to explaining and predicting human behavior in various social-ecological contexts. What is still lacking is a practical framework that bridges disciplinary divides and fundamental differences that lie between psychological and social structural underpinnings of human behavior (Kluver et al. 2014; Seto et al. 2016; Wilson and Dowlatabadi 2007). Addressing social-ecological problems requires an approach that integrates interventions at different levels of processes through which individual behaviors, collective actions, and structural arrangements all operate interactively (Bandura 1999). Together, these levels of analyses 
provide the interdependent micro-macro explanation for social change processes. Current social-ecological systems can transform towards sustainable trajectories if people act to protect natural resources and if social structures provide sufficient platforms to support their actions. In this paper, we have explained how these interdependent processes can be integrated into a more comprehensive framework for social change towards environmental sustainability. Furthermore, we applied the framework to the global wildlife trade and provided high-level problem diagnosis and potential solutions for change.

Behavioral and social structural processes illustrated in the present framework guide change agents to unpack key factors underlying the root cause of social-ecological problems and to understand why pro-environmental actions do or do not occur. Our framework brings about a robust approach to instigating pro-environmental social change drawn upon insights from psychology and sociology and shows key elements and their interactions that can be targeted, operationalized, and evaluated in intervention programs. Another important contribution of the framework is to distinguish the roles that private actions, social-signaling actions, and system-changing actions play in the process of social-ecological transformation. Since transformative change includes large-scale shifts in cultural values and social meanings, approaches that attend to each type of action in behavioral and structural interventions are likely to yield much greater impacts.

So far, reductionist and holistic approaches have separately shown that changes to human actions are possible, either from changes in individual behaviors or in social structural arrangements. With the integration of both approaches, there is a possibility for transformative change required to solve complex social-ecological issues. The aim of the framework is to highlight key considerations and steps for initiating social change processes at different levels and scales and to suggest a more realistic conception and approaches to achieving environmental sustainability.

Acknowledgements This work was supported by the Four Year Doctoral Fellowship Program from the University of British Columbia, the Canada Research Chair Program, and Social Sciences and Humanities Research Council (Insight Grant \#435-2017-1071). We would like to thank Dr. Robin Naidoo, Dr. Jeff Sayer, Dr. Agni Boedhihartono, and members of the CHANS Lab and the Behavioral Sustainability Lab for their helpful pre-reviews and comments.

\section{Declarations}

Conflict of interest The authors declare no conflicts of interests that are relevant to the content of this article.

\section{References}

Abernethy KE, Bodin T, Olsson P, Hilly Z, Schwarz A (2014) Two steps forward, two steps back: the role of innovation in transforming towards community-based marine resource management in Solomon Islands. Glob Environ Chang 28(1):309-321. https:// doi.org/10.1016/j.gloenvcha.2014.07.008

Abson DJ, Fischer J, Leventon J, Newig J, Schomerus T, Vilsmaier U, Lang DJ (2017) Leverage points for sustainability transformation. Ambio 46:30-39. https://doi.org/10.1007/s13280-016-0800-y

Agrawal A (2001) Common property institutions and sustainable governance of resources. World Dev 29(10):1649-1672

Agrawal A (2014) Studying the commons, governing common-pool resource outcomes: some concluding thoughts. Environ Sci Policy 36:86-91. https://doi.org/10.1016/j.envsci.2013.08.012

Agrawal A, Chhatre A, Gerber ER (2015) Motivational crowding in sustainable development interventions. Am Polit Sci Rev 109(3):470-487. https://doi.org/10.1017/S0003055415000209

Aguirre AA, Catherina R, Frye H, Shelley L (2020) Illicit wildlife trade, wet markets, and COVID-19: preventing future pandemics. World Med Health Policy 12(3):256-265. https://doi.org/ 10.1002/wmh3.348

Archer M (1996) Social integration and system integration: developing the distinction. Sociology 30(4):679-699

Asensio OI, Delmas MA (2015) Nonprice incentives and energy conservation. Proc Natl Acad Sci 112(6):E510-E515. https://doi.org/ 10.1073/pnas.1401880112

Baker SE, Cain R, Kesteren FV, Zommers ZA, D'Cruze N, MacDonald DW (2013) Rough trade: animal welfare in the global wildlife trade. Bioscience 63(12):928-938. https://doi.org/10.1525/bio. 2013.63.12.6

Baker K, Baylis K, Bull GQ, Barichello R (2019) Are non-market values important to smallholders' afforestation decisions? A psychometric segmentation and its implications for afforestation programs. For Policy Econ 100:1-13. https://doi.org/10.1016/j. forpol.2018.11.001

Bandura A (1986) Social foundations of thought and action: a social cognitive theory. Prentice-Hall Inc, Englewood Cliffs

Bandura A (1999) Social cognitive theory: an agentic perspective. Asian J Soc Psychol 2:21-41

Bandura A (2001) Social cognitive theory: an agentic perspective. Annu Rev Psychol 52:1-26

Baynes J, Herbohn J, Smith C, Fisher R, Bray D (2015) Key factors which influence the success of community forestry in developing countries. Glob Environ Chang 35:226-238. https://doi.org/10. 1016/j.gloenvcha.2015.09.011

Bennett NJ, Satterfield T (2018) Environmental governance: a practical framework to guide design, evaluation, and analysis. Conserv Lett 11(6):1-13. https://doi.org/10.1111/conl.12600

Bennett NJ, Roth R, Klain SC, Chan K, Christie P, Clark DA, Wyborn C (2017) Conservation social science: Understanding and integrating human dimensions to improve conservation. Biol Cons 205:93-108. https://doi.org/10.1016/j.biocon.2016.10.006

Berkowitz L, Walker N (1967) Laws and moral judgments. Sociometry 30(4):410-422

Blake J (1999) Overcoming the "value-action gap" in environmental policy: tensions between national policy and local experience. Local Environ 4(3):257-278. https://doi.org/10.1080/13549 839908725599

Bodin Ö (2017) Collaborative environmental governance: achieving collective action in social-ecological systems. Science. https:// doi.org/10.1126/science.aan 1114 
Boedhihartono AK, Bongers F, Boot RGA, Dijk JV, Jeans H, Kuijk MV, Zuidema PA (2018) Conservation science and practice must engage with the realities of complex tropical landscapes. Trop Conserv Sci 11:1-7. https://doi.org/10.1177/1940082918779571

Brown MA, Chandler J, Lapsa MV, Sovacool BK (2008) Carbon lockin: barriers to deploying climate change mitigation technologies. Oak Ridge National Laboratory

Buranyi S (2018, November 13) The plastic backlash: What's behind our udden rage and will it make a difference? The Guardian. https://www.theguardian.com/environment/2018/nov/13/theplastic-backlash-whats-behind-our-sudden-rage-and-will-itmake-a-difference

Burgess G, Olmedo A, Veríssimo D, Waterman C (2019) Changing consumer behavior for pangolin products. In: Challender DW, Nash HC, Waterman C (eds) Pangolins: science, society and conservation, 1st edn. Academic Press, Oxford, pp 349-366. https://doi.org/10.1016/b978-0-12-815507-3.00022-8

Byerly H, Balmford A, Ferraro PJ, Wagner CH, Palchak E, Polasky S, Fisher B (2018) Nudging pro-environmental behavior: evidence and opportunities. Front Ecol Environ 16(3):159-168. https://doi.org/10.1002/fee.1777

Callahan MM, Echeverri A, Ng D, Zhao J, Satterfield T (2019) Using the Phylo Card Game to advance biodiversity conservation in an era of Pokémon. Palgrave Commun 5(79):1-10. https://doi. org/10.1057/s41599-019-0287-9

Casoria F, Galeotti F, Villeval MC (2021) Perceived social norm and behavior quickly adjusted to legal changes during the COVID19 pandemic. J Econ Behav Organ 190:54-65. https://doi.org/ 10.1016/j.jebo.2021.07.030

Centola D, Becker J, Brackbill D, Baronchelli A (2018) Tipping points in social convention. Science 360(6393):1116-1119. https://doi.org/10.1126/science.360.6393.1082-d

Challender DW, MacMillan DC (2014) Poaching is more than an enforcement problem. Conserv Lett 7(5):484-494. https://doi. org/10.1111/conl.12082

Chan KMA, Anderson E, Chapman M, Jespersen K, Olmsted P (2017) Payments for ecosystem services: rife with problems and potential for transformation towards sustainability. Ecol Econ 140:110-122. https://doi.org/10.1016/j.ecolecon.2017. 04.029

Chan KMA, Boyd DR, Gould RK, Jetzkowitz J, Liu J, Muraca B, Brondízio ES (2020) Levers and leverage points for pathways to sustainability. People Nature 00:1-25. https://doi.org/10.1002/ pan3.10124

Chapman M, Satterfield T, Chan KMA (2019) When value conflicts are barriers: can relational values help explain farmer participation in conservation incentive programs? Land Use Policy 82:464-475. https://doi.org/10.1016/j.landusepol.2018.11.017

Chenoweth E, Stephan MJ (2011) Why civil resistance works: the strategic logic of nonviolent conflict. Columbia University Press, New York

Chervier C, Le Velly G, Ezzine-de-Blas D (2019) When the implementation of payments for biodiversity conservation leads to motivation crowding-out: a case study from the Cardamoms Forests, Cambodia. Ecol Econ 156:499-510. https://doi.org/10.1016/j. ecolecon.2017.03.018

Chomel BB, Belotto A, Meslin FX (2007) Wildlife, exotic pets, and emerging zoonoses. Emerg Infect Dis 13(1):6-11. https://doi.org/ 10.3201/eid1301.060480

Christensen G, Miguel E (2018) Transparency, reproducibility, and the credibility of economics research. J Econ Lit 56(3):920-980. https://doi.org/10.1257/jel.20171350

Cialdini RB, Goldstein NJ (2004) Social Influence: compliance and conformity. Annu Rev Psychol 55(1):591-621. https://doi.org/ 10.1146/annurev.psych.55.090902.142015
CITES (2019) Convention on international trade in endangered species of wild fauna and flora. https://cites.org/sites/default/files/I/Broch ure_UNEP_CITES_eng.pdf

Craigie ID, Barnes MD, Geldmann J, Woodley S (2015) International funding agencies: Potential leaders of impact evaluation in protected areas? Philosophical Trans R Soc B Biol Sci 370:20140283. https://doi.org/10.1098/rstb.2014.0283

Datta S, Mullainathan S (2014) Behavioral design: a new approach to development policy. Rev Income Wealth 60(1):7-35. https://doi. org/10.1111/roiw.12093

Davis T, Hennes EP, Raymond L (2018) Cultural evolution of normative motivations for sustainable behaviour. Nature Sustain 1(5):218-224. https://doi.org/10.1038/s41893-018-0061-9

Dayer AA, Lutter SH, Sesser KA, Hickey CM, Gardali T (2018) Private landowner conservation behavior following participation in voluntary incentive programs: recommendations to facilitate behavioral persistence. Conserv Lett 11(2):1-11. https://doi.org/ $10.1111 /$ conl.12394

Diani M, McAdam D (2003) Social movements and networks: relational approaches to collective action. Oxford University Press, Oxford

Díaz S, Settele J, Brondízio ES, Ngo HT, Agard J, Arneth A, Zayas CN (2019) Pervasive human-driven decline of life on Earth points to the need for transformative change. Science. https://doi.org/10. 1126/science.aax3100

Dobson AP, Pimm SL, Hannah L, Kaufman L, Ahumada JA, Ando AW, Vale MM (2020) Ecology and economics for pandemic prevention. Science 369(6502):379-381. https://doi.org/10.1126/ science.abc3189

Doughty H, Veríssimo D, Tan RCQ, Lee JSH, Carrasco LR, Oliver K, Milner-Gulland EJ (2019) Saiga horn user characteristics, motivations, and purchasing behaviour in Singapore. PLoS ONE 14(9):1-18. https://doi.org/10.1371/journal.pone.0222038

Doughty H, Milner-Gulland EJ, Lee JSH, Oliver K, Carrasco LR, Veríssimo D (2021) Evaluating a large-scale online behaviour change intervention aimed at wildlife product consumers in Singapore. PLoS ONE 16(3):e0248144. https://doi.org/10.1371/ journal.pone.0248144

Dubois P, Albuquerque P, Allais O, Bonnet C, Bertail P, Combris P, Chandon P (2021) Effects of front-of-pack labels on the nutritional quality of supermarket food purchases: evidence from a large-scale randomized controlled trial. J Acad Mark Sci 49:119_ 138. https://doi.org/10.1007/s11747-020-00723-5

Environment UN (2019) Global environment outlook-GEO-6: healthy planet, healthy people. Nairobi. https://doi.org/10.1017/97811 08627146

Eskew EA, Carlson CJ (2020) Overselling wildlife trade bans will not bolster conservation or pandemic preparedness. Lancet Planet Health 4:e215-e216. https://doi.org/10.1016/S2542-5196(20) 30123-6

Ezzine-de-Blas D, Corbera E, Lapeyre R (2019) Payments for environmental services and motivation crowding: towards a conceptual framework. Ecol Econ 156:434-443. https://doi.org/10.1016/j. ecolecon.2018.07.026

Festinger L (1957) A theory of cognitive dissonance. Stanford University Press, Stanford

Fishbein M, Ajzen I (2010) Predicting and changing behavior: the reasoned action approach. Psychology Press, New York

Freund C, Rahman E, Knott C (2017) Ten years of orangutan-related wildlife crime investigation in West Kalimantan, Indonesia. Am J Primatol 79:1-11. https://doi.org/10.1002/ajp.22620

Geels FW, Schot J (2007) Typology of sociotechnical transition pathways. Res Policy 36(3):399-417. https://doi.org/10.1016/j.respol. 2007.01.003

Giddens A (1984) The constitution of society. Polity Press, Cambridge, UK 
Gifford R (2011) The Dragons of Inaction: psychological barriers that limit climate change mitigation and adaptation. Am Psychol 66(4):290-302. https://doi.org/10.1037/a0023566

Gifford RD (2014) Environmental psychology matters. Annu Rev Psychol 65:541-579. https://doi.org/10.1146/annur ev-psych-010213-115048

GlobeScan (2020) Opinion survey on COVID-19 and wildlife trade in 5 Asian markets: findings from survey in March 2020. GlobeScan \& WWF. https://globescan.com/wp-content/uploads/2020/ 04/GlobeScan_WWF_Coronavirus_Public_Opinion_Survey_ Full_Report_2April2020.pdf

Granovetter M (1978) Threshold models of collective behavior. Am J Sociol 83(6): 1420-1443

Green KM, Crawford BA, Williamson KA, DeWan AA (2019) A meta-analysis of social marketing campaigns to improve global conservation outcomes. Soc Mark Q 25(1):69-87. https://doi. org/10.1177/1524500418824258

Greenfield S, Veríssimo D (2019) To what extent is social marketing used in demand reduction campaigns for illegal wildlife products? Insights from elephant ivory and rhino horn. Soc Mark Q 25(1):40-54. https://doi.org/10.1177/1524500418813543

Grima N, Singh SJ, Smetschka B, Ringhofer L (2016) Payment for Ecosystem Services (PES) in Latin America: analysing the performance of 40 case studies. Ecosyst Serv 17:24-32. https:// doi.org/10.1016/j.ecoser.2015.11.010

Gruber JS (2010) Key principles of community-based natural resource management: a synthesis and interpretation of identified effective approaches for managing the commons. Environ Manag 45(1):52-66. https://doi.org/10.1007/ s00267-008-9235-y

Haidt J (2001) The emotional dog and its rational tail: a social intuitionist approach to moral judgment. Psychol Rev 108(4):814834. https://doi.org/10.1037/0033-295X

Handberg ØN, Angelsen A (2019) Pay little, get little; pay more, get a little more: a framed forest experiment in Tanzania. Ecol Econ 156:454-467. https://doi.org/10.1016/j.ecolecon.2016.09.025

Hargreaves T (2011) Practice-ing behaviour change: Applying social practice theory to pro-environmental behaviour change. J Consum Cult 11(1):79-99. https://doi.org/10.1177/1469540510 390500

Heidbreder LM, Bablok I, Drews S, Menzel C (2019) Tackling the plastic problem: a review on perceptions, behaviors, and interventions. Sci Total Environ 668:1077-1093. https://doi.org/10. 1016/j.scitotenv.2019.02.437

Henrich J, Heine SJ, Norenzayan A (2010) Most people are not WEIRD. Behav Brain Sci 466:29. https://doi.org/10.1017/S0140 525X0999152X

Hübschle A (2017) Fluid interfaces between flows of rhino horn. Global Crime 18(3):198-217. https://doi.org/10.1080/17440 572.2017 .1345680

Hummel D, Maedche A (2019) How effective is nudging? A quantitative review on the effect sizes and limits of empirical nudging studies. J Behav Exp Econ 80:47-58. https://doi.org/10.1016/j. socec.2019.03.005

IPBES (2020) Workshop report on biodiversity and pandemics of the intergovernmental platform on biodiversity and ecosystem services. Intergovernmental Platform on Biodiversity and Ecosystem Services, Bonn

IPBES (2019) Summary for policymakers of the global assessment report on biodiversity and ecosystem services. Bonn, Germany. Retrieved from https://ipbes.net/system/tdf/ipbes_global_asses sment_report_summary_for_policymakers.pdf?file $=1 \&$ type $=$ node\&id $=35329$

IPCC (2019) Summary for policymakers. In: Shukla PR, Skea J, Calvo Buendia E, Masson-Delmotte V, Pörtner H-O, Roberts DC, Zhai P, Slade R, Connors S, van Diemen R, Ferrat M, Haughey E,
Luz S, Neogi S, Pathak M, Petzold J, Portugal Pereira J, Vyas P, Huntley E, Kissick K, Belkacemi M, Malley J (eds) Climate change and land: an IPCC special report on climate change, desertification, land degradation, sustainable land management, food security, and greenhouse gas fluxes in terrestrial ecosystems (In press)

Jayachandran S, Laat JD, Lambin EF, Stanton CY, Audy R, Thomas NE (2017) Cash for carbon: a randomized trial of payments for ecosystem services to reduce deforestation. Science 357(6348):267-273

Kendal D, Raymond CM (2018) Understanding pathways to shifting people's values over time in the context of social-ecological systems. Sustain Sci. https://doi.org/10.1007/s11625-018-0648-0

Kidd LR, Garrard GE, Bekessy SA, Mills M, Camilleri AR, Fidler F, Adams VM (2019) Messaging matters: a systematic review of the conservation messaging literature. Biol Cons 236(May):92-99. https://doi.org/10.1016/j.biocon.2019.05.020

Kim DA, Hwong AR, Stafford D, Hughes DA, O’Malley AJ, Fowler JH, Christakis NA (2015) Social network targeting to maximise population behaviour change: a cluster randomised controlled trial. Lancet 386(9989):145-153. https://doi.org/10.1016/S01406736(15)60095-2

Kinzig AP, Ehrlich PR, Alston LJ, Arrow K, Barrett S, Buchman TG, Saari D (2013) Social norms and global environmental challenges: the complex Interaction of behaviors, values, and policy. Bioscience 63(3):164-175. https://doi.org/10.1525/bio.2013. 63.3 .5

Kitade T, Naruse Y (2020) Crossing the red line: Japan's exotic pet trade. TRAFFIC, Tokyo

Klain SC, Olmsted P, Chan KMA, Satterfield T (2017) Relational values resonate broadly and differently than intrinsic or instrumental values or the NEP. PLoS ONE 12(8):1-12

Kluver J, Frazier R, Haidt J (2014) Behavioral ethics for Homo economicus, Homo heuristicus, and Homo duplex. Organ Behav Hum Decis Process 123(2):150-158. https://doi.org/10.1016/j. obhdp.2013.12.004

Koh LP, Li Y, Lee JSH (2021) The value of China's ban on wildlife trade and consumption. Nat Sustain 4:2-4. https://doi.org/10. 1038/s41893-020-00677-0

Kollmuss A, Agyeman J (2002) Mind the gap: why do people act environmentally and what are the barriers to pro environmental behavior? Environ Educ Res. https://doi.org/10.1080/13504 620220145401

Krishnasamy K, Zavagli M (2020) Southeast Asia: at the heart of wildlife trade. TRAFFIC, Southeast Asia Regional Office, Petaling Jaya. https://www.traffic.org/site/assets/files/12648/sea-trapsfebruary-2020.pdf

Kristal AS, Whillans AV (2020) What we can learn from five naturalistic field experiments that failed to shift commuter behaviour. Nat Hum Behav 4:169-176. https://doi.org/10.1038/ s41562-019-0795-z

Kunda Z (1990) The case for motivated reasoning. Psychol Bull 480(3):482-483. https://doi.org/10.1037/0033-2909.108.3.480

Larson LR, Stedman RC, Cooper CB, Decker DJ (2015) Understanding the multi-dimensional structure of pro-environmental behavior. J Environ Psychol 43:112-124. https://doi.org/10.1016/j.jenvp. 2015.06 .004

Legros S, Cislaghi B (2020) Mapping the social-norms literature: an overview of reviews. Perspect Psychol Sci 15(1):62-80. https:// doi.org/10.1177/1745691619866455

Lertzman R, Baragona K (2016) Reducing desire for ivory: a psychological guide to address ivory consumption. World Wildlife Fund. https://c402277.ssl.cf1.rackcdn.com/publications/981/ files/original/ReducingDesireforIvory_011917_print.pdf?14848 47912 
Levine J, Chan KMA, Satterfield T (2015) From rational actor to efficient complexity manager: exorcising the ghost of Homo economicus with a unified synthesis of cognition research. Ecol Econ 114:22-32. https://doi.org/10.1016/j.ecolecon.2015.03.010

Lin N (2001) Social capital: a theory of social structure and action. Cambridge University Press, New York

Lockton D, Harrison D, Stanton NA (2010) The design with intent method: a design tool for influencing user behaviour. Appl Ergon 41:382-392. https://doi.org/10.1016/j.apergo.2009.09.001

Lord CG, Ross L, Lepper MR (1979) Biased assimilation and attitude polarization: the effects of prior theories on subsequently considered evidence. J Pers Soc Psychol 37(11):2098-2109. https:// doi.org/10.1037/0022-3514.37.11.2098

Lounsbury M, Ventresca M, Hirsch PM (2003) Social movements, field frames and industry emergence: a cultural-political perspective on US recycling. Soc Econ Rev 1:71-104. https://doi.org/10. 1093/soceco/1.1.71

Mascia MB, Mills M (2018) When conservation goes viral: the diffusion of innovative biodiversity conservation policies and practices. Conserv Lett 11(e12442):1-9. https://doi.org/10.1111/conl. 12442

Maxwell SE, Lau MY, Howard GS (2015) Is psychology suffering from a replication crisis?: what does "failure to replicate" really mean? Am Psychol 70(6):487-498. https://doi.org/10.1037/a0039400

McGinnis MD, Ostrom E (2014) Social-ecological system framework: initial changes and continuing challenges. Ecol Soc. https://doi. org/10.5751/ES-06387-190230

McNamara J, Rowcliffe M, Cowlishaw G, Alexander JS, NtiamoaBaidu Y, Brenya A, Milner-Gulland EJ (2016) Characterising wildlife trade market supply-demand dynamics. PLoS ONE 11(9):1-18. https://doi.org/10.1371/journal.pone.0162972

Meadows D (1999) Leverage points: places to intervene in a system. Sustainability Institute Hartland

Milkoreit M, Hodbod J, Baggio J, Benessaiah K, Calderón-Contreras R, Donges JF, Werners SE (2018) Defining tipping points for social-ecological systems scholarship: an interdisciplinary literature review. Environ Res Lett 13:033005. https://doi.org/10. 1088/1748-9326/aaaa75

Miller DT, Prentice D (2016) Changing norms to change behavior. Annu Rev Psychol 67(1):339-361. https://doi.org/10.1146/annur ev-psych-010814-015013

Mols F, Haslam SA, Jetten J, Steffens NK (2015) Why a nudge is not enough: a social identity critique of governance by stealth. Eur J Polit Res 54:81-98. https://doi.org/10.1111/1475-6765.12073

Moorhouse TP, Balaskas M, D'Cruze NC, Macdonald DW (2017) Information could reduce consumer demand for exotic pets. Conserv Lett 10(3):337-345. https://doi.org/10.1111/conl.12270

Naidoo R, Weaver LC, Diggle RW, Matongo G, Stuart-Hill G, Thouless C (2016) Complementary benefits of tourism and hunting to communal conservancies in Namibia. Conserv Biol 30(3):628638. https://doi.org/10.1111/cobi.12643

Nijman V (2017) Orangutan trade, confiscations, and lack of prosecutions in Indonesia. Am J Primatol 79(11):1-4. https://doi.org/ 10.1002/ajp. 22652

Nuwer R (2020) To prevent next coronavirus, stop the wildlife trade, conservationists say. Retrieved 26 June 2020, from https://www. nytimes.com/2020/02/19/health/coronavirus-animals-markets. html

Nyborg K, Anderies JM, Dannenberg A, Lindahl T, Schill C, Schlüter M, De Zeeuw A (2016) Social norms as solutions: policies may influence large-scale behavioral tipping. Science 354(6308):4243. https://doi.org/10.1126/science.aaf 8317

O'Brien K (2015) Political agency: the key to tackling climate change. Science 350(6265):1170-1171
O'Brien $\mathrm{K}$ (2018) Is the $1.5^{\circ} \mathrm{C}$ target possible? Exploring the three spheres of transformation. Curr Opin Environ Sustain 31:153160. https://doi.org/10.1016/j.cosust.2018.04.010

O'Brien K, Sygna L (2013) Responding to climate change: the three spheres of transformation. In: Proceedings of transformation in a changing climate, 19-21 June 2013, Oslo, Norway. University of Oslo, pp 16-23. ISBN 978-82-570-2000-2

Olsson P, Folke C, Berkes F (2004) Adaptive comanagement for building resilience in social-ecological systems. Environ Manage 34(1):75-90. https://doi.org/10.1007/s00267-003-0101-7

Ostrom E (1990) Governing the commons: the evolution of institutions for collective action. Cambridge University Press, Cambridge. https://doi.org/10.1017/CBO9780511807763

Otto IM, Donges JF, Cremades R, Bhowmik A, Hewitt RJ, Lucht W, Schellnhuber HJ (2020) Social tipping dynamics for stabilizing Earth's climate by 2050. Proc Natl Acad Sci USA 117(5):23542365. https://doi.org/10.1073/pnas.1900577117

Paluck EL, Shepherd H, Aronow PM (2016) Changing climates of conflict: a social network experiment in 56 schools. Proc Natl Acad Sci 113(3):566-571. https://doi.org/10.1073/pnas.1514483113

Pierson P (2000) Increasing returns, path dependence, and the study of politics. Am Polit Sci Rev 94(2):251-267

Rare and The Behavioural Insights Team (2019) Behavior change for nature: a behavioral science toolkit for practitioners. Arlington. https://www.bi.team/publications/behavior-change-for-nature-abehavioral-science-toolkit-for-practitioners

Raymond L, Weldon SL, Kelly D, Arriaga XB, Clark AM (2014) Making change: norm-based strategies for institutional change to address intractable problems. Political Res Q 67(1):197-211. https://doi.org/10.1177/1065912913510786

Reckwitz A (2002) Toward a theory of social practices. Eur J Soc Theory 5(2):243-263. https://doi.org/10.1177/13684310222225432

Rizzolo JB (2021) Wildlife consumption: the roles of legalization and wildlife farming. Global Ecol Conserv. https://doi.org/10.1016/j. gecco.2020.e01390

Roe D, Booker F (2019) Engaging local communities in tackling illegal wildlife trade: a synthesis of approaches and lessons for best practice. Conserv Sci Practice. https://doi.org/10.1111/csp2.26

Roe D, Dickman A, Kock R, Milner-Gulland EJ, Rihoy E, T'Sas-Rolfes M (2020) Beyond banning wildlife trade: COVID-19, cconservation and development. World Dev. https://doi.org/10.1016/j.world dev.2020.105121

Rogers EM (1958) Categorising the adopters of agricultural practices. Rural Sociol 23(4):346-354

Rogers EM (2003) Diffusion of innovations, 5th edn. Free Press, New York

Ryan B, Gross NC (1943) The diffusion of hybrid seed corn in two Iowa communities. Rural Sociol 8(1):15-24

Sas-Rolfes M, Challender DWS, Hinsley A, Veríssimo D, MilnerGulland EJ (2019) Illegal wildlife trade: scale, processes, and governance. Annu Rev Environ Resour 44:201-228. https://doi. org/10.1146/annurev-environ-101718-033253

Sawyer RK (2005) Social emergence: societies as complex systems. Cambridge University Press, Cambridge. https://doi.org/10.1017/ CBO9780511734892

Sayer J, Sunderland T, Ghazoul J, Pfund J-L, Sheil D, Meijaard E, Buck LE (2013) Ten principles for a landscape approach to reconciling agriculture, conservation, and other competing land uses. Proc Natl Acad Sci 110(21):8349-8356. https://doi.org/10.1073/pnas. 1210595110

Schutte NS, Bhullar N (2017) Approaching environmental sustainability: perceptions of self-efficacy and changeability. J Psychol 151(3):321-333. https://doi.org/10.1080/00223980.2017.12891 44 
Seto KC, Davis SJ, Mitchell R, Stokes EC, Unruh G, Ürge-Vorsatz D (2016) Carbon lock-in: types, causes, and policy implications. Annu Rev Environ Resour 41:425-452. https://doi.org/10.1146/ annurev-environ-110615-085934

Shah AK, Oppenheimer DM (2008) Heuristics made easy: an effortreduction framework. Psychol Bull 134(2):207-222

Shakya HB, Stafford D, Hughes DA, Keegan T, Negron R, Broome J, Christakis NA (2017) Exploiting social influence to magnify population-level behaviour change in maternal and child health: study protocol for a randomised controlled trial of network targeting algorithms in rural Honduras. BMJ Open 7(3):1-13. https://doi.org/10.1136/bmjopen-2016-012996

Shove E (2010) Beyond the ABC: Climate change policy and theories of social change. Environ Plan A 42(6):1273-1285. https://doi. org/10.1068/a42282

Shove E, Pantzar M, Watson M (2012) The dynamics of social practice: everyday life and how it changes. SAGE Publications, London. https://doi.org/10.2307/j.ctv16r56.8

Slovic P, Västfäll D, Erlandsson A, Gregory R (2017) Iconic photographs and the ebb and flow of empathic response to humanitarian disasters. Proc Natl Acad Sci USA 114(8):640-644. https:// doi.org/10.1073/pnas.1613977114

Soman D, Hossain T (2020) Successfully scaled solutions need not be homogenous. Behav Public Policy. https://doi.org/10.1017/ bpp. 2020.24

Stern PC (2000) Toward a coherent theory of environmentally significant behavior. J Soc Issues 56(3):407-424. https://doi.org/ 10.1007/BF00640994

Störmer N, Weaver LC, Stuart-hill G, Diggle RW, Naidoo R (2019) Investigating the effects of community-based conservation on attitudes towards wildlife in Namibia. Biol Cons 233:193-200. https://doi.org/10.1016/j.biocon.2019.02.033

Sunstein CR (2017) Nudges that fail. Behav Public Policy 1(1):4-25. https://doi.org/10.1017/bpp.2016.3

Sunstein CR (2020) The meaning of masks. J Behav Econ Policy 4:5-8. https://doi.org/10.2139/ssrn.3571428

Sunstein CR, Reisch LA (2014) Automatically green: behavioral economics and environmental protection. Harv Environ Law Rev 38:127-158. https://doi.org/10.3868/s050-004-015-0003-8

Sussman R, Gifford R (2019) Causality in the theory of planned behavior. Pers Soc Psychol Bull 45(6):920-933. https://doi.org/10. $1177 / 0146167218801363$

Swim JK, Stern PC, Doherty TJ, Clayton S, Reser JP, Weber EU, Howard GS (2011) Psychology's contributions to understanding and addressing global climate change. Am Psychol 66(4):241-250. https://doi.org/10.1037/a0023220

Teel TL, Manfredo MJ (2010) Understanding the diversity of public interests in wildlife conservation. Conserv Biol 24(1):128-139. https://doi.org/10.1111/j.1523-1739.2009.01374.x

Thaler RH, Sunstein CR (2008) Nudge: Improving decisions about health, wealth, and happiness. Yale University Press, New Haven

Thomas-Walters L, Hinsley A, Bergin D, Burgess G, Doughty H, Eppel S, Veríssimo D (2020) Motivations for the use and consumption of wildlife products. Conserv Biol. https://doi.org/10.1111/cobi. 13578

Tittensor DP, Harfoot M, Mclardy C, Britten GL, Kecse-nagy K, Malsch K (2020) Evaluating the relationships between the legal and illegal international wildlife trades. Conserv Lett. https://doi. org/10.1111/conl.12724

TRAFFIC and The Behavioural Insights Team (2019) Reducing demand for illegal wildlife: designing effective messages. TRAFFIC, Cambridge. https://www.traffic.org/site/assets/files/12124/ dr-good-practice-guidelines-messages-final.pdf

Turner JC, Hogg MA, Oakes PJ, Reicher SD, Wetherell MS (1987) Rediscovering the social group: a self-categorization theory. Brasil Blackwell, Cambridge
Tversky A, Kahneman D (1974) Judgment under uncertainty: heuristics and biases. Science 185(4157):1124-1131

United Nations (2019) Global sustainable development report 2019: the future is now-science for achieving sustainable development. United Nations, New York

Vadrot ABM, Jetzkowitz J, Stringer LC (2016) Correspondence: IPBES disciplinary gaps still gaping. Nature 530:160

Valente TW (1996) Social network thresholds in the diffusion of innovations. Soc Netw 18(1):69-89. https://doi.org/10.1016/03788733(95)00256-1

van Gestel LC, Adriaanse MA, de Ridder DTD (2020) Beyond discrete choices-investigating the effectiveness of a proximity nudge with multiple alternative options. Front Psychol 11:1211. https:// doi.org/10.3389/fpsyg.2020.01211

van Uhm DP (2016) The illegal wildlife trade. In: Siegel D (ed) Inside the world of poachers, smugglers and traders. Springer, Switzerland. https://doi.org/10.1007/978-3-030-13666-6_3

Veríssimo D, Wan AKY (2019) Characterizing efforts to reduce consumer demand for wildlife products. Conserv Biol 33(3):623633. https://doi.org/10.1111/cobi.13227

Veríssimo D, Vieira S, Monteiro D, Hancock J, Nuno A (2020) Audience research as a cornerstone of demand management interventions for illegal wildlife products: demarketing sea turtle meat and eggs. Conserv Sci Pract 2(3):1-14. https://doi.org/10.1111/ $\operatorname{csp} 2.164$

Vigors B (2018) Reducing the consumer attitude-behaviour gap in animal welfare: the potential role of 'Nudges.' Animals 8(12):1-23. https://doi.org/10.3390/ani8120232

Wang Y, Turvey ST, Leader-Williams N (2020) Knowledge and attitudes about the use of pangolin scale products in Traditional Chinese Medicine (TCM) within China. People Nat 2:903-912. https://doi.org/10.1002/pan3.10150

Waylen KA, Fischer A, McGowan PJK, Milner-Gulland EJ (2013) Deconstructing community for conservation: why simple assumptions are not sufficient. Hum Ecol 41(4):575-585. https:// doi.org/10.1007/s10745-013-9594-8

White K, Habib R, Hardisty DJ (2019) How to SHIFT consumer behaviors to be more sustainable: a literature review and guiding framework. J Mark 83(3):22-49. https://doi.org/10.1177/00222 42919825649

Wilson C, Dowlatabadi H (2007) Models of decision making and residential energy use. Annu Rev Environ Resour 32(1):169-203. https://doi.org/10.1146/annurev.energy.32.053006.141137

Witter R, Satterfield T (2018) Rhino poaching and the "slow violence" of conservation-related resettlement in Mozambique's Limpopo National Park. Geoforum. https://doi.org/10.1016/j.geoforum. 2018.06.003

Xie J, Sreenivasan S, Korniss G, Zhang W, Lim C, Szymanski BK (2011) Social consensus through the influence of committed minorities. Phys Rev E 84(1):1-9. https://doi.org/10.1103/PhysR evE.84.011130

Young HP (2015) The evolution of social norms. Annu Rev Econ 7(1):359-387. https://doi.org/10.1146/annurev-econo mics-080614-115322

Zhao J, Naito R, Luo Y, Deans N (2021, October 13) Getting everyone to act on climate change. SDG Action. https://sdg-action.org/getti ng-everyone-to-act-on-climate-change

Publisher's Note Springer Nature remains neutral with regard to jurisdictional claims in published maps and institutional affiliations. 